\title{
SITC $\mathrm{N}$
}

\section{WHAT MAKES A SUCCESSFUL HOTEL REPUTATION MANAGEMENT STRATEGY: QUALITATIVE RESEARCH ON TRIPADVISOR HOTEL REVIEWS}

\author{
Edina Ajanović ${ }^{1 \star}$, Beykan Çizel ${ }^{2}$ \\ ${ }^{1}$ Institute of Social Sciences, Akdeniz University, Antalya, Turkey \\ ${ }^{2}$ Tourism Faculty, Akdeniz University, Antalya, Turkey
}

\begin{abstract}
:
Nowadays, the concept of reputation management in hospitality industry is related to the efforts of the hotel management to find the best solutions for handling the reviews and comments of hotel guests left on one of numerous social media channels. The introduction of Web 2.0 technologies has brought about innovation in terms of how contemporary society interacts, allowing people to generate unique content to be published on their preferred social media channel. Hospitality industry faces numerous challenges concerning handling of the user generated content, especially on travel review sites and is trying to be actively involved in creating and maintaining its reputation. The aim of this research paper is to address the vital elements of successful reputation management of a hotel property. In order to do so, the authors have conducted the content analysis of TripAdvisor reviews and responses to these for the hotel property targeted as an example of a good reputation management strategy. The research results will point out the aspects of reputation management hotel managers should pay attention to and should serve as a useful guideline for the hotel's social media marketing activities.
\end{abstract}

\section{Key words:}

hotel reputation management, hotel social media marketing, TripAdvisor reviews, content analysis.

\section{INTRODUCTION}

In today's fast-changing and global market, organizations that were able to build and sustain strong corporate brand and reputation are on a good path to gain a competitive advantage compared to rival companies. In most organizations, the departments responsible for reputation management are marketing, communications and public relations (Martin \& Hetrick, 2006). Reputation management is usually treated in the same way as public relations, even though these two concepts differ significantly. Public relations are viewed as a guidance which creates and maintains useful relationships between the organizations and public on which its success or failure depends (Cutlip, Center, \& Broom, 2003, p. 6). The concept of public relations inquires a list of the main activities that make up practice such as publicity, advertising, lobbing etc.

On the other hand, reputation can be defined as a social construction, based on the image we reflect in the eyes of others (Griffin, 2002). If we reflect this on the corporation's reputation, it is based on what other people think about this company and the efforts of the company will make towards defining its reputation. What is more important is that reputation is not based solely on external perceptions, but on the behaviour supported by these perceptions (Griffin, 2002).

Modern digital age has changed the way corporate reputation should be perceived and managed. The companies should place more emphasis on information management, especially the information that may influence how people perceive the company. Along with technology evolution, communicating company's business objective via the Internet as the basic channel for interacting with past and potential future guests has become of vital importance. The Internet has changed the traditional approach where organizations maintain and control its owner value. Nowadays, regular Internet users have the power to influence the corporate base by sharing their opinions on different travel web platforms. This means that companies are no longer able to strictly control the company's information and content published on the web; and it will lead to tough struggle with the aim to preserve the positive image in the eyes of customers.

Reputation management is a vital strategic issue for those companies that mainly rely on their intangible attributes in building competitiveness such as creativity, innovation, intellectual capital and high levels of services (Kay, 2004). Accordingly, the hotel industry is highly dependable on positive reputation that may affect customers' purchasing decisions. When it comes to hotel business, reputation management usually addresses the proper use and proactive dealing with the content shared on travel review sites (TripAdvisor, HolidayCheck, Zoover, TopHotels etc.), different social media channels such as social network sites (Facebook, My Space), video and image sharing media (YouTube, Instagram) and personal travel blogs. Online 
platforms where travellers can share their experience, evaluations and comments about tourism products and services are accepted as an important data source. The evolution of e-trade in tourism industry started with development of the Internet and especially Web 2.0 technologies which introduced numerous opportunities. Owning to the introduction of Web 2.0 technologies, people are able to purchase, evaluate and share their thoughts on different social media platforms. Therefore, these new platforms and reviews shared on them can be used as an important source of data in today's academic research.

By engaging in these different channels within the virtual environment, the hoteliers are trying to maintain good relationships with their guests after their stay in the hotel, correct or at least state the awareness of negative issues that occurred during the stay and also leave the impression of the property that really cares about providing its customers with the ultimate hotel experience. Nowadays, this is one of the ways to retain the old customers by creating the firm relationships and attract new potential hotel guests promising the similar loyal bonds in the future. Regardless of the importance of a proper reputation management strategy on a hotel business performance and success, there is a lack of academic research on this topic. It is usually discussed in the professional hotel journals, web pages and online reputation management companies' forums and blogs (some of them are hospitalitynet.org, tnooz.com, hotelmarketing. com, trustyou.com). The successful case studies and benefits of strategic approach towards reputation management issues prove its efficiency and encourage other industry representatives to pay more attention to it. This paper is among the first that tried to gain a deeper insight into the important aspects of successful online reputation management practices and provide hotel managers with some useful recommendations about how to strategically deal with the issue. The aim is to enrich the overall academic knowledge about successful social media marketing strategies in hotels and form a basis for future research on this topic.

\section{RESEARCH AIM AND SCOPE}

The aim of this study is to attempt to identify the elements and aspects of positive hotel reputation management practices. After analysing the prominent web sites dealing with new hotel marketing strategies, the decision was made to use Hotel Bel-Air in Los Angeles Beverly Hills as a successful case study concerning reputation management strategy on the TripAdvisor comments. In this study, the authors conducted the content analysis of the hotel reviews left by the guests of Hotel Bel-Air on TripAdvisor and the replies of the hotel management to these reviews. The reasons why TripAdvisor travel review site has been chosen is because it can be considered one of the largest travel sites by millions of travellers and a wide variety of travel choices and planning features. TripAdvisor branded sites make up the largest travel community in the world, reaching 340 million unique monthly visitors, and more than 225 million reviews and opinions covering more than 4.9 million accommodations, restaurants and attractions (TripAdvisor, 2015). Travel review web sites such as TripAdvisor are some of the most commonly used when it comes to searching for information about tourism destinations and the main cri- teria in decision making about tourism destinations (Black \& Kelly, 2009). TripAdvisor web site is one of the most popular platforms used in academic research papers $(\mathrm{Au}$, Buhalis \& Law, 2014; Ekiz, Khoo-Lattimore \& Memarzadeh, 2010; Kim, Lim \& Brymer, 2015; O'Connor, 2010) in which content analysis is being the dominantly used method in examining the travellers' attitudes towards hotel properties, effects of online reviews on hotel performance etc.

Upon data collection process, researchers applied an objective coding scheme in order to derive systematically comparable information through content analysis (Berg, 2007 , p. 238). Each of the researchers independently coded and categorized the data from the travel review replies into different categories. The categories researchers used in this content analysis were determined inductively with the "researchers "immersing" themselves in travel review replies in order to identify the dimensions or themes that seemed meaningful to the producers of each message" (Abrahamson, 1983, p. 286). Differences in categorization between the researchers were discussed until a consensus was reached and the final category and sub-category structure was derived.

\section{RESULTS \& DISCUSSION}

Out of the total of 470 reviews found on Hotel Bel-Air Los Angeles TripAdvisor account by August 15, 2015, 364 reviews with hotel management's replies were examined. Those that were not included in the analysis were either not in English or dated from the period when replies of hotel management on travel reviews were not provided. The hotel started with the practice of answering to both positive and negative TripAdvisor reviews in September 2010 and the management has written replies on almost all TripAdvisor reviews up to this date. As a result of the content analysis, the four elements of a successful online reputation management can be derived: creating unique content about the property, personalization, emphasizing property values and dealing with negative comments (Figure 1). Sub-categories under each category are presented in Table 1.

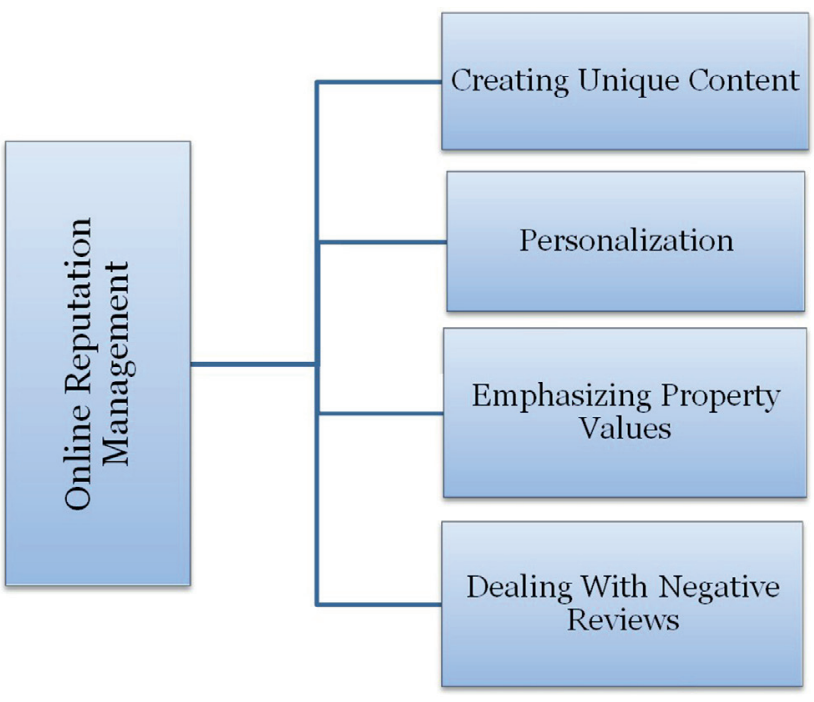

Fig 1. The most important aspects of successful online reputation management 
Table 1. Elements of the hotel online reputation management

Hotel Online Reputation Management

\begin{tabular}{|c|c|c|c|}
\hline $\begin{array}{l}\text { Creating } \\
\text { Unique } \\
\text { Content }\end{array}$ & $\begin{array}{l}\text { Personaliza- } \\
\text { tion }\end{array}$ & $\begin{array}{l}\text { Emphasiz- } \\
\text { ing Property } \\
\text { Values }\end{array}$ & $\begin{array}{l}\text { Dealing } \\
\text { With Nega- } \\
\text { tive Reviews }\end{array}$ \\
\hline $\begin{array}{l}\text { Guest words } \\
\text { Dealing } \\
\text { with transi- } \\
\text { tion periods }\end{array}$ & $\begin{array}{l}\text { Apprecia- } \\
\text { tion } \\
\text { Repeating } \\
\text { customers' } \\
\text { experience } \\
\text { Special } \\
\text { treatment } \\
\text { for loyal } \\
\text { guests }\end{array}$ & $\begin{array}{l}\text { Property } \\
\text { features } \\
\text { Details } \\
\text { Service } \\
\text { quality } \\
\text { Hotel stuff }\end{array}$ & $\begin{array}{l}\text { Encourag- } \\
\text { ing cus- } \\
\text { tomers to } \\
\text { comment } \\
\text { Throughout } \\
\text { notification } \\
\text { Personal } \\
\text { engagement }\end{array}$ \\
\hline
\end{tabular}

\section{Creating unique content about property}

In today's Internet market, every company is in search for a unique, organic and interesting content that will position the company's web site on the top of Google search lists. Therefore, many companies including the hotels are trying to make the best use of different channels found on the web and survey as many users as possible. If properly used, the replies to hotel reviews on TripAdvisor may be used as a perfect content generator coming directly from the users. Not only will the level of credibility and trust in the hotel rise, but it is also the great marketing and advertising of the hotel property with interesting slogans.

"It is wonderful to hear you were "treated like an A-list star"- this is exactly how it should be" "Thank you for considering us 'the best place in the Los Angeles area to relax.'

"... I particularly like this room category because of the outdoor patio and its views on the canyon, and your description of your evening spent in "the hot tub with a glass of wine every night looking at the stars" sounds idyllic".

These direct quotations show how the hotel management uses the unique content coming from the guest to describe and promote their own property. This sentence is a great example of how to use the guest's words for selfpromotion, and it is completely free.

With the same strategy of using the user generated content, hotel management was able to successfully deal with the transition period such as a hotel renovation.

"..It is wonderful to read that you decided to stay with us since the reopening of the hotel, and that you found it "streamlined and modernized rather than changed." We felt a tremendous responsibility to maintain the hotel's beloved look and feel it is very comforting to know that you felt as if you were in the "same space."

This is a good example of how the manager skilfully uses the words and explanations from the guest to address the topic of renovation. With only two sentences, the manager was able to express the general attitude and responsibility of the whole hotel management to continue with the recognizable service (tremendous responsibility to maintain the hotel's beloved look) and by repeating the guests word of mouth, it proves that these efforts were successful (streamlined and modernized rather than changed and felt as if you were in the "same space").

\section{Personalization}

Every review reply was named on the regarding Trip Advisor use, and gratefulness for time and effort to write each review was expressed without exception. The manager constantly repeated all positive impressions of a certain guest.

"...delighted to read that you enjoyed every aspect of your stay, "from the grown up atmosphere", to the "renovated rooms and good casual al fresco steakhouse", to the spa."

"I am thrilled to hear you loved every aspect of your "little getaway" with us...from your room, to the beautiful gardens, to the pool and service."

In this way, it can be concluded that the person who wrote the reply really appreciated the time and the content written for the hotel. Therefore, the manager was paying special attention to devoting certain part of the reply to repeat the positive aspects of the guest's stay. Not only does this confirm the importance the hotel gives to each positive word coming from a reviewer, but once again, it highlights positive features and aspects of hotel services provided in the hotel Bel-Air.

When it comes to a review that comes from a loyal customer, it can be noticed that managers already know the person who wrote it, as he/she has been staying in this hotel and leaving positive reviews for years. Special warmth can be noticed in correspondence which goes beyond a regular review about the hotel stay and polite reply to it. A nice example might be found in one reply to the review that came from the guest who expressed its highly positive experience with this hotel while mentioning to be a loyal customer for years. Special emphasis was on enjoyment in the beautiful hotel atmosphere which was at the same time inspired him to write few chapters of his new book. The extract from the manager's reply to this review was as follows:

"I must also say that it is an incredible honour to know that Hotel Bel-Air was the inspiration for one of the chapters from "In His Name". I look forward to reading a book and there is perhaps no higher compliment coming from an esteemed author like yourself."

This quotation not only shows that the manager knows which guests provided the positive review, but it has also given a space in the reply to name the title of the book on which the guest was working while staying in the hotel. In this way, it was also doing a beneficial activity for the guest and one's profession as it was marketing book title form the esteemed author. Not only does this contribute to the positive and highly satisfactory loyalty relationship between the guest and the hotel management, but it is a real example to all potential visitors of the kind of treatment and relationship they can expect from the hotel.

\section{Emphasizing property values}

The majority of management's replies on TripAdvisor guest's reviews reveal that the great emphasis is placed on the hotel units such as restaurants, spa centres, good location and conformity of rooms, and they try to promote the quality of service throughout replies.

"It's great to know that you enjoyed every aspect of your stay...from your suite accommodations, to Wolfgang Puck at Hotel Bel-Air, to our La Prairie Spa." 
Based on the hotel manager's replies, it can be implied that hotel management greatly emphasizes their tendency to provide high quality services to all their guests. This is clearly stated through "Five Star service" structure that repeats throughout reviews.

"...I very much appreciate your note about the Five Star service provided to you by our service professionals."

"... what means the most is to know that you received Five Star service throughout your stay."

The idiom Five Star service is something expressed and derived as the light motive through numerous other replies. Sometimes after a highly positive rating it is used as a great summary of all high class services provided to hotel guests. This can be a good way to express and promote business philosophy and goals of the hotel property.

In hotel replies to TripAdvisor reviews, one can notice a special sense for details which carries greater importance than when being read in a regular guest review.

"... and I am happy to know you enjoyed the bathrobes they are very popular with all of our guests!"

By emphasizing a small detail in the guest's review such as enjoyment in bathrobes, leaves the impression that this hotel pays attention to every detail when providing its high class service. By writing about this detail in the reply, the manager managed to give special attention to this small detail, but with a simple sentence generalized the positive aspects it has on the hotel guests.

By emphasizing property values, the authors refer only to promoting tangible but also intangible features of the hotel property. Therefore, the hotel that was subject of the analysis places special emphasis on the hotel staff. Every time when a staff member was mentioned by name, whether in a positive or negative context, general manager devoted special part of his reply to this aspect. If it the comment was negative, it was to be discussed with the responsible department and any valuable comment from the review would be notified to all the staff. If the positive comment was provided, the general manager would give full credits to this reply.

"Please note I will make sure to share your lovely comments with all our team members, as it will mean a great deal to them.

"I must also thank you for your feedback regarding our great team of service professionals, especially Juan in housekeeping. Please know that I will be sure to share your kind words with him, as it will mean a great deal to him to know that he had such a positive impact on your stay."

\section{Dealing with negative comments}

Firstly, it can be observed that the management encourages guests to provide the hotel management with feedback about their negative experiences with the services provided. This will actually encourage the management to prevent them from providing Five Star service to all its guests, which is stated as the main goal of this hotel.

"...I am sorry to hear about negative experience with the room service, but I appreciate your feedback as this is the only way we can improve our shortcomings."

"Please know that I have been addressing all of these shortcomings with our team and working with them to ensure that we prevent them from occurring in the future"
Almost all the reviews that had some negative aspects were followed by the reply clearly stating that the comment will the forwarded to the hotel team from different departments and authority levels and that all the efforts will be put into preventing that similar issues repeat. This is a good example of how much importance is assigned to each review no matter if it is positive or negative.

"I am, however, sorry to hear that your experience at the restaurant was disappointing and will have our restaurant manager, Rosie Butler, reach out to you to better understand where we fell short of your expectations".

If there is a short in service even the name of the responsible manager could be provided so that it can get deeper insight into the problem. This is practically a continuation of hotel efforts to further investigate in order to provide high-quality services and their willingness not to leave it as only a few words mentioned in the negative context in the guest review. It gives a positive impression to a potential future visitor of this hotel, as this explicitly shows that the hotel is ready to deal with any issue that may occur during your stay, while giving the hotel guests' reviews a full credit.

"Thank you again for taking the time to share your valuable feedback. I truly hope that we will be able to welcome you back in the near future and restore your faith in us. I would ask that you reach out to me directly so I may personally oversee your next stay at Hotel Bel-Air."

In addition to notifying the department responsible for shortcomings in providing service, hotel manager offers the guests who had some negative experience during their stay to get in contact with them personally. This gives the additional assurance that in case of a repeated visit, the management wishes to guarantee the perfect stay showing how important it is for the management to provide the supreme hotel experience to each individual guest.

\section{CONCLUSION}

Nowadays, when online technologies have been rapidly developing, all business properties, and especially hotels, have to keep properties to a high standard, awarded by the positive electronic word-of-mouth. In order to do so, the hotels should clearly define their business goals to be achieved and communicated in the Internet environment. Thus, hotel management should develop a comprehensive and effective strategy on how to manage different social media marketing channels. Due to the market coverage, good reputation and media that gather hundreds and thousands of users all over the world, Tripadvisor.com stands out as a vital media that the hotel should use as a starting point in building its online reputation. This paper examines the successful online reputation management strategy on this travel review site and proposes fundamental elements of the vital online reputation management: creating unique content about property, personalization, emphasizing property values and dealing with negative comments. In addition, there are several guidelines regarding reputation management strategy that may facilitate general efforts to improve social media marketing performance.

Personalization with each guest that leaves review on the hotel Trip Advisor account; By expressing gratitude for taking extra time to write a review about the hotel and address each guest by its user name means that hotel 
management appreciates the comment coming from each individual guest. It is necessary to maintain the aspects of hotel services and features that made the stay in a certain hotel positive, as it will leave an impression that management reads carefully the comments each guest provides and considers equally important every aspect that can guarantee supreme hotel experience. Once this type of bond has been established between the hotel and the guest, there is nothing that could prevent the guest from becoming one of the most loyal ones.

New review - new chance; every new review is a good chance for a unique marketing and promotion activity stressing out the most important elements of a hotel offer. By repeating the most positively evaluated aspects of the reviews, the hotel management will be able to generate a unique content about property features and introduce guidelines for potential guests that are about to come to the hotel.

Giving equal attention and importance to both positive and negative comments; after mentioning all positive aspects of one's stay, it is also of vital importance to mention the points where hotel failed to fulfil guest's expectations. These findings about the importance of responding to negative comments are consistent with those of Chen and Xie (2008) and Kim, Lim and Brymer (2015), where it is also stated that the hotel willingness to make up for service failure will result in higher financial performance of the hotel. This will leave the impression among guests that this hotel pays full attention to all aspects of one's review and it does not avoid but rather faces the problem wherever and whenever it occurs. If the management succeeds in leaving a positive impression and the sense of confidence with the reader, it means that these marketing and communication media are being successfully used.

Hotel reputation management philosophy should become part of hotel business culture; taking care that both positive and negative aspects derived from the reviews found on one of the biggest travel review web sites is properly transmitted to each department and each employee. Each person in hotel business chain should know how to behave in order to improve the current services or continue maintaining a high level of professional services, taking into consideration the guests' comments on social media.

Gain trust and leave the impression of a highly reliable hotel property; Nowadays, most of the people will not visit the hotel's official web page because they do not believe in the validity of information and experiences shared on it. If the hotel manages to establish sustainable reputation and be flexible in answering to both positive and negative comments in the Internet environment perceived as a neutral by guests, the hotel is on a good path to remain competitive on the contemporary hotel market.

\section{REFERENCES}

Abrahamson, M. (1983). Social Research Methods. Englewood Cliffs. In: Berg, B.L. (2007). Qualitative research methods for the social sciences (pp. 238-267). Boston, MA: Pearson Education.

Au, N., Buhalis, D., \& Law, R. (2014). Online Complaining Behavior in Mainland China Hotels: The Perception of Chinese and Non-Chinese Customers, International Journal of Hospitality \& Tourism Administration, 15 (3), 248-274.

Black, H.G., \& Kelley, S.W. (2009). A storytelling perspective on online customer reviews reporting service failure and recovery. Journal of Travel and Tourism Marketing, 26 (1), 169-179.

Berg, B.L. (2007). Qualitative research methods for the social sciences (6th ed.). Boston, MA: Pearson Education.

Chen, Y., \& Xie, J. (2008). Online consumer review: word-ofmouth as a new element of marketing communication mix. Management Science, 54 (3), 477-491.

Cutlip, S.M., Center, A.H., \& Broom, G.M. (2000). Effective Public Relations (8th ed.). Englewood Cliffs, NJ: Prentice Hall.

Ekiz, E., Khoo-Lattimore, C., \& Memarzadeh, F. (2010). Air the anger: investigating online complaints on luxury hotels. Journal of Hospitality and Tourism Technology, 3 (2), 96-106.

Griffin, G. (2002). Reputation management. Oxford: Capstone Publishing.

Kim, W.G., Lim, H., \& Brymer, R.A. (2015). The effectiveness of managing social media on hotel performance. International Journal of Hospitality Management, 44, 165-171.

Kay, J. (2004). The truth about markets: why some nations are rich but most remain poor. London: Penguin.

Martin, G., \& Hetrick, S. (2006). Corporate Reputations, Branding and Managing People: A Strategic Approach to HR. Oxford: Butterworth Heinemann.

O'connor, P. (2010). Managing a hotel's image on trip advisor. Journal of Hospitality Marketing \& Management, 19, 754-772.

TripAdvisor. (2015). About TripAdvisor. Retrieved May 4, 2015, from http://www.TripAdvisor.com/PressCenter-c6-About_Us.html 